\title{
The Experiences and Perceptions of "amakrwala" (Graduated Initiates) towards the Traditional Male Circumcision Practice in Eastern Cape, South Africa
}

\author{
J. G. Kheswa \\ T. Nomngcoyiya \\ P. Adonis \\ S. Ngeleka \\ Department of Psychology, University of Fort Hare, Private Bag X 1314, Alice, 5700, South Africa. \\ Email: jkheswa@ufh.ac.za; Email : 201006646@ufh.ac.za; Email : 201000971@ufh.ac.za; Email: 201001690@ufh.ac.za
}

\section{Doi:10.5901/mjss.2014.v5n20p2789}

\begin{abstract}
"Ubukrwala" (being a graduated initiate) is regarded as the crucial stage in the initiation ritual among the Xhosa adolescent males in the Eastern Cape, South Africa, as a passage to manhood. The present study sought to explore the experiences and perceptions of amakrwala towards the traditional male circumcision practice in Nkonkobe Municipality, Alice. Many scholars identified the following factors as primary contributory factors leading to traditional male circumcision: culture, respect from the community, participation in traditional activities and moral values. A focus group interview with five male participants (who were purposively sampled), aged 16-19, was employed in this study. The results revealed that most participants reported endurance, rebirth of self-respect and responsibility. Furthermore, they emphasized that cooperation with traditional nurses was important in their healing process. The recommendations are that traditional male circumcision workshops must be organized by government.
\end{abstract}

Keywords: Traditional male circumcision, Amakrwala (graduated initiates), Culture, Manhood.

\section{Introduction}

Traditional male circumcision practice in many African cultures is linked with rites of passage that seeks to fulfil the needs of society and individuals (Peltzer \& Kanta, 2009). Mogotlane, Ntlangule and Ongunbanjo (2004), believe that among Xhosa speaking people, male circumcision is an initiation that is usually performed to symbolize the boys maturity as well as transition of adolescent male from being "inkwenkwe" (boy) to being "indoda" (a man). Within Eastern Cape, Xhosa communities, hundreds of boys aged 18-23 attend traditional circumcision schools as part of the initiation process (Ngxokolo, 2011). After the initiates return home, they are guided through a 6-months protocol, during this period; they are traditionally called "amakrwala" (graduated initiates). According to Ntombana (2009) "ubukrwala" (being a graduated initiate) is regarded as the crucial stage in the initiation ritual among the Xhosa speakers and at this stage an initiate is presented to society with a new status, new clothes, new rights, duties and responsibilities. The transition from boyhood to manhood is featured by the an initiate's adoption of specific behaviour, dress code, and a new name all these would be appropriate to the initiate's newly acquired stage.

According to Papu and Verster (2006) before initiates can be called "amakrwala" (graduated initiates) they have to be re-incorporated into the community and this usually begins by chasing the initiates to the river and this process is called ritual washing. After that process, the initiates will be anointed by the man who is selected by the family and who is very respectful. The aim of choosing the respected man to anoint the initiates is to transfer his qualities to the initiates so that they also become respectful towards other people.

Circumcised men are expected to take on greater social responsibility in their communities, acting as negotiators in family disputes, weighing decisions carefully and cooperating with elders (Vincent, 2008). Gitywa (1976) indicates that the most important thing in the life of a graduated initiate (ikrwala) is a positive change in behaviour. The graduated initiates (amakrwala) must differ from uncircumcised boys "amakhwenkwe" by exercising internal locus of control, prosocial behaviour and psychological maturity (Breet, Myburgh \& Poggenpoel, 2010)

However, there are immense challenges that are entrenched in traditional male circumcision practice in South 
Africa especially, in the Eastern Cape Province. These problems range from incorrectly performed circumcisions, incompetent attendants, unhealthy surroundings, infection of circumcision wounds, gangrene of the penis, severe haemorrhage, respiratory infection, dehydration leading to penile amputation, torture and assault resulting in serious injuries, or even deaths (Peltzer \& Kanta, 2009). The aforementioned challenges have adversely weakened the social capital that is associated with this practice and has changed the way traditional male circumcision is being perceived nationally, continentally and globally. It is fundamental to take a different context and validate these challenges especially in the area where traditional male circumcision is still held at higher esteem and to hear the experiences and the perceptions of those young men who still went on to perform the ritual in the face of deadly atrocities' that have been widely reported in the media and other mass communication avenues against traditional male circumcision. Based on the premises above, the research questions were formulated as follows;

- What are the experiences and perceptions of graduated initiates in traditional male circumcision practice?

- In what way has traditional male circumcision impacted on your manhood (e.g. in your families, society and school)?

- How have been your emotional experiences and psychological make-up like in the process of healing?

- Explain the teachings received while you were at the initiation school? (E.g. moral-values, self- respect, responsibility).

\section{Aims and Objectives}

The aim of this research is to explore the experiences and perceptions of "amakrwala" (graduated initiates) towards the traditional male circumcision practice in Nkonkobe Municipality, Alice - Eastern Cape, South Africa.

\subsection{Specific Objectives}

- To explore the experiences and perceptions of graduated initiates with regards to traditional male circumcision practice.

- To assess the impact of traditional male circumcision on their manhood

- To establish how emotional experiences and psychological make-up has been like in the healing process.

- To examine the teachings received by the graduated initiates while at the initiation school.

\subsection{Significance of the study}

During the period of traditional male circumcision practice in the Eastern Cape, majority of initiates experience complications due to negligence by traditional surgeons and traditional nurses (Gaya, 2010). Therefore, this study seeks to conduct empirical research in form of focus-group interviews with the intent to establish the significance of the traditional male circumcision. Furthermore, the study will also be vital in a sense that the custodians of this traditional practice will use the findings in formulation of their own policies that will strengthen, restore, and enhance the value and dignity of traditional male circumcision practice. This could lead to a more integrated approach to traditional male circumcision practice itself.

\section{Research Methodology and Design}

Creswell (2008) is of the view that methodology entails the process of collecting concepts, ideas, theories, and assumptions. The methodology answers the question "how are the research investigations going to be executed" (de Vos et al., 2011). A cross-sectional study explorative qualitative study was conducted and the study population and sample size comprised of males from Alice, Golf Course Village who had performed traditional male circumcision practice. The data of the experiences and perceptions of "amakrwala" (graduated initiates) in the traditional male circumcision practice was gathered from purposively selected five (5) males who were graduated initiates and had gone through the rite of passage traditionally during the period of June. Data collected from the participants included their demographic features such as: age, race. 


\subsection{Procedure}

Data was gathered from five (5) male participants from Alice, Golf Course Village which comprised only "amakrwala" (graduated initiates). In October 2013, five questionnaires were administered to the participants (amakrwala) and consent forms were signed by all participants before the completion of questionnaire and the responses were good because all were completed. The researchers were given the permission by the Ward Councillor of Alice Town and Golf Course and by the Association of lingcibi and Amakhankatha in Alice.

\section{Trustworthiness}

The trustworthiness of qualitative research generally is often questioned by positivists, perhaps because their concepts of validity and reliability cannot be address in the same way in naturalistic research (Shenton, 2004). Arguably many qualitative paradigm researchers prefer to make use of different terminology to distinguish themselves from quantitative approach. According to Lincoln and Guba (1995), proposed few requirements that should be taken into consideration by qualitative researchers in pursuit of a trustworthy research. For example, the following criteria: credibility, neutrality, and transferability.

\subsection{Credibility}

According to Shenton (2004) one of the key requirements addressed by qualitative researchers is that of internal validity which seek to ensure that their study tests or measures what it was intended to measure. Lincoln and Guba (1985) refer to this as credibility. They believe that internal validity is based on the assumption that there's a single tangible reality to be measured. Hence, in this study of the exploration of the experiences and perceptions of "amakrwala" (graduated initiates) in traditional circumcision practice is based on the findings of human experiences as they perceived by the aforementioned participants.

\subsection{Neutrality}

Neutrality refers to the degree to which the findings are a function solely of the participants and conditions of the research and not of other biases, motivation and perspectives (Guba, 1981). Krefting (1991) is of the view that in qualitative research, objectivity is the requirement of neutrality and is achieved through proper distance between the researcher and subjects that minimizes biases. In this study the researchers managed to maintain objectivity or value-free research as it is the criteria for the scientific method in research by asking questions which address their experiences and perceptions of the traditional male circumcision practice.

\subsection{Transferability}

Transferability is concerned with the extent to which the findings of one study can be applicable to other situations (Shenton, 2004). Creswell (2008) postulates that transferability is achieved when the findings of the study fit into contexts outside the study situation and when its audience views its findings as meaningful and applicable in terms of their own experiences.

\section{Ethical Considerations}

According to Walker (2010), ethical considerations are concerned with the protection of the rights and interests of research participants who are giving their time to help in the research. These rights included the right to privacy, the right to confidentiality, the right to informed consent as well as the right to voluntary participation or not to be compelled to participate in the study (de Vos et al., 2005).The researchers obtained informed consent from each participant prior administered questionnaires to get the responses of "amakrwala"- (graduated initiates).

The researchers tried by all means to abide to ethics issues by employing the following measures or guidelines:

- Research permission letter was submitted to the Ward Councillor of Alice and Association for lingcibi naMakhankatha in Alice requesting to conduct the research.

- Advantages of the research study were explained to the participants. Participants were given an opportunity to withdraw from the study if they so wish, but none of the participants withdrew and they managed to respond 
and completed all the question guide and questionnaires that was administered to them.

- In terms of assuring anonymity and confidentiality, participants were requested not to use their real names during focus group discussion and write their names in the informed agreement form but rather use participant numbers that were assigned to them during the study.

- No physical or psychological harm reported by the participants as the interview schedules (i.e. questionnaires) were endorsed by our supervisor at the University of Fort Hare, Alice Campus.

\section{Theoretical Framework}

Theoretical framework provides the definition of relationship between all the variables so that the researcher can understand the theorized relationships between them. It enables researchers to make logical sense of the relationships of the variables and factors that have been deemed relevant to the problem (Terre Blanche, Durrhim \& Painter, 2006). Theoretical framework encompasses theories or issues in which a study is embedded and it also serves as an orientation for gathering facts since it specifies the type of facts to be systematically observed. Although this study could be informed by various theories, the researchers have considered the application of socio-cultural, social support, and selfdetermination theories.

\subsection{Socio-cultural perspective}

According to Peplau and Taylor (1997), socio-cultural perspective draws our attention to the significance of culture, and then seeks to understand ways in which specific features of culture affect people's thoughts, feelings, and behaviour. De Kock, et al (1997) highlight few values that are synonymous with being an African such as: importance of the family, importance of the group (clan), respect of elders, fear of God (Uqamata), as well as a deep commitment to sustain meaningful community life through shared problems and sorrows. Culture refers to aspects of the social environment that control human conduct. This view is evident in the word that: "umntu ngumntu ngabantu" which means to be a human is to relate with others (Venter, 2011). Culture gives people a general design for living and patterns for interpreting their reality, a sense of who they are, where they are going to and how they fit into society (sense of belonging). Culture in any society is characterised by sharing the rituals and preservation of societal identity (Venter, 2011).

\subsection{Social support theory}

According to Segal, Gerdes and Steiner (2007) social support theory strengthens social interaction between people in which an individual has a source of psychological, emotional and physical assistance. They further argue that there is also a notion of team work, team spirit, sharing of information and companionship and people are connected to one another through a social network. Social support theory is an appropriate conceptual frame as it thrives on rich social capital built by community support systems, making interactions that are accompanied by love, mutual trust, interdependence, and a feeling of togetherness (Kang'ethe, 2011).

\subsection{Self-determination theory}

Most people's motivation relies on what their needs and wants, usually the focus is on personal needs satisfaction as the basis for motivational behaviour (Robbins et al, 1998). The theory of self-determination in this sense is one of the theories that can better explain as to how young men despite of all the dangers that are associated with traditional male circumcision practice but still determined to go through with the rite of passage from boyhood to manhood. Ryan (2009) believes that self-determination theory is a macro-theory of human motivation, personality development, and well-being. This theory focuses especially on volitional or self-determined behaviour and the social and cultural conditions that promote it. According to Oliver, Markland, Hardy and Petheric (2008) self-determination theory provides support for the satisfaction of innate (inborn) basic psychological needs for competence; autonomy and relatedness promote the natural processes of internalization, integration of the self and healthy psychological development.

\section{Discussion of the Research Results}

After employing axial coding, the following themes emerged from the study 


\subsection{Respect of Elders}

Majority of the research participants indicated that after they have traditionally circumcised, they acquire respect in all spheres of the society such as at home from their families, at school by their fellow school mates as well as by the entire society. They have highlighted the fact that they are men, now they are being form part of the decision-making within their families and in society. Furthermore, they are expected to participate in cultural and traditional activities as part of the responsibility of being in the manhood stage. Some of the participants made these remarks:

"I receive respect from the younger people and I am not being undermined like before".

"I think it is very important because I got many things that can take my life in a right way now I have respect"

"Imbeko ibalulekile ngoko kufuneka uhloniphe omncinci ngalo ndlela nam ndawubona umehluko"

(Respect is very important thus you need to respect all people (big and small) and I can see the difference).

"Esikolweni amakhwenkwe andinika intlonipho enkulu ngoba akekho nomnye ondibiza ngegama yonke nje ikwekwe indiphethe ngentlonipho"

(Boys at school give a lot of respect and there is no one that calls me name. All boys give me respect).

Venter (2011) explained that traditional circumcision is very important to the Xhosa boy as it serves as a passport to be accepted and respected by the community. He further posited that as circumcised boy get recognition and acceptance from the community, it is different to uncircumcised boys as they are regarded as unclean and as a person whom no good can be expected. Teachings and admonition words that graduated initiates got before they went through initiation, whilst in the initiation school and when they graduated help them to know what respect is all about. In most situations respect which is received from others contributes toward enhancement of self-esteem.

\subsection{Decision-Making within the Family}

Many research participants indicated that some of the benefits of undergoing traditional circumcision practice are that in their families they are now part of the decision-making as in comparison with the period when they were still regarded as "amakhwenkwe" (boys). The significance of manhood according to them is shown by the numerous occasions where they are being consulted in serious issues that affect the family and their input is regarded as valuable. The following sentiments were made by some of the respondents:

"Ekhayeni kukho umahluko omkhulu ngoba phambi kokuba kwenziwe izigqibo ndiyabizwa ndibe yinxalenye yalo meeting nam". (There is a difference at home because before they make decisions, they call me so that I can be part of a meeting).

"At home I am given all the respect as a man, such that now I have a say in whatever decision take within the family"

Mavundla (2009) stipulated that the initiation ritual is of great importance to the Xhosa tribe as it gives the man an opportunity and authority to be fully involved in decision-making process on household and tribal issues.

\subsection{Participation in Traditional Activities}

All the research respondents highlighted the issue of participating in traditional activities as one of the turning points of having circumcised traditionally in the sense that they are now expected as men to take part in such activities. In the future they will also be expected to conduct such activities as part of their culture and tradition. One of the research respondents said:

"When I was a boy I was not allowed to participate in any traditional ceremonies but now that I am a man I have an authority to attend whatever I want even funerals"

Another respondent on the issue of participation to traditional activities made the following remarks:

"Ekuhlaleni ukhona umehluko ngoba nam ngoku ndiyajongeka njengomntu kwaye ndiyaya nasemicimbini" (There is a difference now I am respected by the community and I even attend traditional activities).

Ntombana (2009) claimed that men after circumcision are expected to assume new responsibilities, including participation in traditional meetings and be responsible for community activities. He further argues that, among Xhosa speaking being "indoda" (a man) means that, you are able to share in the full rights and duties of the community. 


\subsection{Endurance}

Vincent (2008) stated that endurance is one of the qualities that the initiates taught while they are in the initiation school. Endurance build certain character traits which are patience, courage, resilience and strength which will help the initiates to withstand any adversaries that he will experience during his life. Endurance is one aspect that is highlighted by the participants, teachings that they have got from older men who already experience the conditions of circumcision help the participants during traditional circumcision.

One of the respondents said:

"Through all the thinking an answer will appear that, you wanted to be a man now you have to endure the circumstances. There are also be experienced men giving you all the advices to fight for your health".

Another of the respondents made the following comments:

"Bekubuhlungu kona kodwa ke bekunyanzelekile, andizisoli nganto ngoba ukuze ube yindoda isiXhosa kufanele uzivile intlungu". (It was very painful but it was supposed to be like that I do not regret anything because to be a man you need to endure pains).

Endurance is associated with one of the Bible scriptures in the book of Romans 5: 3 as it states that "we gladly suffer, because we know that suffering helps us to endure. And endurance builds character, which gives us a hope that will never disappoint us (The Holy Bible, 2003).

\subsection{Co-Operation with the Nurses}

The participants stated that being co-operative during healing process helped a lot. The good working relationship between them and the traditional nurses was put forward as the reason they healed without complications. They were told not drink water as this is going to have an effect to their healing process and cooperate with what they have been told. The following sentiments were made:

"Ukungaseli kwamamanzi kundincedile ngoba ndiye ndaphila kwamsinya. (Because, I did not drink water it helps me a lot as I healed very quickly).

\subsection{Receiving Advice and Help}

Findings indicated that, when the participants were in the Initiation School support system was there to help them through the healing process. Traditional nurses were helpful during this hard time: one of the Respondents indicated that:

\footnotetext{
" ekuqaleni bekungekho themba lokuba ndizakuba right kodwa ikhankatha lindikhuthaza". (At first the was no hope that my wound will heal but the traditional nurse motivates me)

"There are will be experienced men giving you all the help and advices to fight for your health"

"Even your biological father does not smile to you but he keep on saying be strong it will rain and pass"
}

According to Mhlahlo (2009), the traditional nurse has the responsibility of teaching the initiate about manhood. He further postulated that although the traditional nurse is responsible for teaching "eBhumeni" (initiation hut) he also depends on the support of men who normally stay "eBhumeni". These men provide this support through giving advice concerning the dressing of the wound and by teaching an initiate about manhood.

\subsection{Self-Respect}

The notion of self-respect is one of the values which most participants highlighted during interviews. They further postulated that for people to respect you, you need to respect yourself first. Because they are traditionally circumcised, they believe in their worth as human beings and trying to be the best. Some participants shared the following sentiments with regard to self-respect:

"I got many things, first thing is to respect myself before I respect other men"

"I was taught that, a man has to respect himself before he respect other people. I mean a man does not drink, sleep 


\section{around but build a family"}

"Now I know I should respect myself".

Raatma (2002) maintains that self-respect means being proud of yourself and what you have achieve. She further postulates that, to respect yourself you honour your own thoughts and feelings. As researchers during an interview we identify that, for "Amakrwala" to be respected by other people, it is very important to respect themselves first then they can be able to respect other people. Because they are traditionally circumcised they believe in their worth as human beings and trying to be the best. Regarding the issue of multiple partners, it is clear that the initiates expressed selfrespect as opposed to engagement to risky sexual behaviour, which is in agreement with the study conducted by Gwata (2009) where the respondents expressed that boys are the one who would drink alcohol publicly, disrespect elders and violates the rights of women. By being encouraged to be sexually wise, this research is in line with the findings by Niang and Boiro (2007), which emphasized that initiates should practise safe-sex or resume sexual relations when their foreskins are completely healed.

\subsection{Good Role Model}

Analysed data indicated that participants put an emphasis on the importance of being role models. They acknowledge that to go through traditional male circumcision helped them to learn how to become good role models. They explained that to be a man means you need to be exemplary to your siblings and other youth in the society.

"You have to be a good example to your brothers and sisters and respect them".

"I mean man does not drink, sleep around"

"If you drink alcohol drink responsible and not do silly things to your parents, they must not even see you drunk".

Spearman and Harrison (2010) advance the view that a good role-model is someone who is admired and who possesses and projects positive qualities that help the person who observes these qualities to develop and grow personally and professionally. This means that the people are inspired to follow in his footsteps.

\subsection{Moral Values}

Equally important, the findings pointed out that the participants explained how the traditional male circumcision helped them to learn about how they can conduct themselves in their families and community. They learnt that the man should not involve himself in behaviour which is not acceptable to his family and the community at large. The views were underscored by the following statements:

\footnotetext{
"When you reach the stage of manhood you are told how does a man live or should behave that includes the people you should engage with in order to have dignity"

"If you drink alcohol, drink responsible. Behave as a man you claim to be and not merge yourself with misleading people. Respect elders and listen to your parents and the way you dress must be dignified, ways you talk do not yell at someone and you no longer play in the streets as though you were a boy, it's all for your dignity"

"Other father said to me my boy, you are the man now but the man is man with action, do what is right for everyone. A man is living under the truth, respect and loyalty".
}

Mhlahlo (2009) argued that a man should conduct himself as an adult. This means that when a boy is circumcised he should stop having many girlfriends. Instead he must get married and build his own family. He further argued that a true man must not involve himself in anti-social behaviour. For example, a man should stay away from violence and criminal activities. Huitt (2004) emphasized the importance of values and morals. He stated that these are codes we live by in a civil and just society. They are what we use to guide our interactions with others, with our friends and family. Our values and morals are reflection of our spirituality and they are what we hope to model for our children because children do watch us as they develop their own sense of right and wrong.

\subsection{Responsibility}

The majority of the participants highlighted the importance of being a man. They explained that when you are a man you are given a responsibility to take care of your family (parents, sisters and brothers). They further advocated that when you are a man you have a responsibility of taking a wife and marry and build your own household. They believed that the 
teachings that they received impacted positively to their manhood as they know that as men they have responsibilities to their families and the society. The following affirmed to what the participants had to say:

"There is lot of change in myself, I can look after my family and do things my parents can't do. I look after my brothers and sisters. I don't want them to be poor like me".

"A man is responsible for his brothers and sisters because a man should bring food for the people in the house. A man should build a family and get married".

"xanduva le ndoda lukhulu ngoba zonke izinto zijongwe yiyo"

(A man has huge responsibility because, everything depends on him).

Gaya (2010) argued that during the period of initiation school men are trained on how to care for their families, due to the fact that they are the protectors and providers of their households. He further argues that they need to have visions on how to take care for their households and all these they are trained in initiation schools. When researchers did interviews with "amakrwala" (participants) responsibility was one of the important aspects they come up with and taught during initiation. According to them (amakrwala) the teachings that they received impacted positively to their manhood as they know that as men they have responsibilities to their families and the society.

\section{Recommendations}

\subsection{Traditional male circumcision workshops by government}

During the informal interaction with the Association of "iingcibi" (traditional surgeons) and "amakhankatha" (traditional nurses) in Alice, they suggested that the government should conduct traditional male circumcision workshop in order to encourage the bogus circumcisors to get knowledge and skills that will enable them to perform this traditional initiation appropriately and thoroughly without any complications or deaths. They further suggested that areas of the Eastern Cape Province that are still at the helm of performing this practice should work very closely with those areas that are found with flaws every circumcision season to share skills and expertise of performing traditional male circumcision.

\subsection{Cultural education programmes by traditional circumcision custodians}

It is high time that the custodians of traditional male circumcision to conduct cultural education programmes to encourage communities to go back to the roots and reclaim this traditional practice. This needs a robust cultural education initiative that should involve communities, parents, and young boys who are most vulnerable to this practice to be made aware of the procedures and processes that one needs to take to undergo traditional male circumcision practice as well as being taught about the dangers that are associated with this practice.

\subsection{Collaboration between culture custodians and government}

It is very clear that the current regulations and legislations of traditional circumcision is dysfunctional due to the fact that government is being accused by the traditional circumcision custodians for having not consulted them during the draft of the current legislation. Therefore, culture custodians and government should both go back to the drawing board and come up with policies, regulations, and procedures as well as implementation thereof, in order to stop the bogus circumcisors and protect the lives of innocent young men who fall victims of the false initiation that is performed in the name of the tradition or culture.

\section{Limitations of the Study}

The size of the sample in the study was smaller than the anticipated sample because of the sensitivity of the research topic and the smaller numbers of participants who were willing to share the information with regard to traditional male circumcision practice with the researchers, but the goal of the study has been achieved by ensuring the use of research ethics. Although this study can be transferable into contexts outside the study situation but it cannot be generalized due to small number of participants that have been used in the study. The findings of qualitative research are specific to a small number of particular environments and individual, therefore; it's impossible to demonstrate that the findings and conclusions are applicable to other situations and populations. 


\section{Conclusion}

Although this practice has been heavily criticized by vast a number of media houses, print media, audio and visual media as well as by researchers due to the flaws that implanted this practice such as death of the initiates, penis amputations and other complications. But the literature and the research findings have clearly outlined the social capital embedded to traditional male circumcision practice in terms of shaping and moulding the behaviour and men of great calibre. The research findings also clearly indicated that some areas in the Eastern Cape are still at the helm in terms of ensuring the appropriate performance of this practice especially, in the midst of all the controversy surrounding the traditional male circumcision practice. However, the role of the custodians of this practice, civil society, government remains significant as far as ensuring, monitoring and promotion of the smooth operation of this traditional practice in order to avoid all the complications related to it. The current approach to traditional male circumcision practice has proved to be dysfunctional as it is striving for desperate strategies which in their nature seek to undermine the rights of people to their cultural practice.

\section{Acknowledgements}

The researchers would like to acknowledge the support and motivation of the University of Fort Hare, Alice Campus, the Faculty of Social Sciences and Humanities, The Department of Social Work/Social Development and Department of Psychology for the provision of resources and guidance. Also to the Golf Course community and the Association of lingcibi naMakhankatha in Alice for giving us a permission to conduct the study in their own backyard without restrictions.

\section{References}

Creswell, J.W. (2008). Research Design Qualitative: Quantitative \& Mixed methods Approach. (3rd ed). Sage Publications Ltd: United States of America.

De Kock, D., Hall, T., Hayden, W., Katan, J., Kuse, H., Lombart, J. , Osie-Hwedie, K., Steyn, J.N., Triegaart, J.D \& Van Zyl, M.A.(1997). Indigenisation in Social and Community Work education: affordable social provision and the Institute for Indigenous Theory and Practise; HSRC Cooperative Research Programme.

De Vos, A.S., Strydom, H., Fouche, C.B. \& Delport, C.S.L. (2011). Research at grass roots for social sciences and human service professions. (4th ed). Van Schaik Publishers: Pretoria.

Gaya, J. (2010). A Man is not a Man if he cannot stand the Trial of Initiation School: Transformation from Boyhood to Manhood breedingground for unwanted disease and death. (LLM Thesis). University of Namibia: Namibia

Gitywa, V.Z. (1976). Male initiation in the Ciskei: formal incorporation into Bantu society. Unpublished Doctoral Dissertation. Fort Hare University.

Gwata, F. (2009). Traditional Male Circumcision: What Is Its Socio-Cultural Significance Among Young Xhosa Men? Centre for Social Science Research. № 264.

Huitt, W. (2004). Moral and character development. Educational Psychology Interactive, Valdosta State University: Valdosta.

Krefting, L. (1991). Rigor in Qualitative Research: The Assessment of Trustworthiness, The American Journal of Occupation Therapy, Vol.45 (3), 214-221.

Lincoln, Y.S. \& Guba, E.G. (1985). Naturalistic inquiry. Sage: Beverly Hills. USA

Mavundla, T.R., Netswera, F.G., Bottom, M. \& Toth, F. (2009). Rationalisation of Indigenous Male Circumcision as a Sacred Religious Customs: Heath beliefs of Xhosa Men in South Africa. SAGE: Pretoria.

Mhlahlo, A. (2009) what is manhood? The Significance of Traditional Circumcision in the Xhosa Initiation Ritual. M PHIL Thesis. Stellenbosch University: Stellenbosch.

Mogotlane, S.M., Ntlangulela, J.T. \& Ogunbanjo, B.G. (2004). Mortality and morbidity among traditionally circumcised Xhosa boys in the Eastern Cape Province, South Africa. Curationis 27 (2), 57-62.

Niang, C.I. \& Boiro, H. (2007). "You can also cut my finger!" Social Construction of Male Circumcision in West Africa, A Case Study of Senegal and Guinea- Bissau. Reproductive Health Matters, Vol.15 (29), 22-23.

Ntombana, L. (2009). Xhosa Male Initiation \& Teaching of Moral Values: An Exploration of the Traditional Guardians in Teaching the Initiates. Indilinga African journal of Indigenous Knowledge System, (8) 73-84.

Peplau, L.A. \& Taylor, S.E. (1997). Socio-cultural perspective in Social Psychology: Current Readings. New Jersey. USA: Prentice Hall, Inc

Peltzer, K. \& Kanta, X. (2009). Medical circumcision and manhood initiation rituals in the Eastern Cape, South Africa: A post intervention evaluation. Culture, Health \& Sexuality, Vol. 11 (1), January 2009, 83-97.

Peltzer, K., Nqeketo, A., Petros, G. \& Kanta, X. (2008). Attitudes of Preinitiates towards Traditional Male Circumcision in the context of HIV in the Eastern Cape, South Africa: Social Behaviour Personality, Society for Personality Research (Inc.), 36 (8), 1023-1034.

Raatma, L. (2002). Self-Respect. Capston Press: USA

Ryan, R. (2009). Self-determination Theory and Wellbeing. University of Bath, Wellbeing in Developing Countries Review 1- June 2009. 
Segal, E.A, Gerdes, K.E, \& Steiner, S. (2007). An introduction to the profession of Social Work. Becoming a change agent. (2nd ed): Thomson Brooks/Cole.

Shenton, A.K. (2004). Strategies for ensuring trustworthiness in qualitative research projects , Education for Information, Vol.22, 63-75. Spearman \& Harrison, L. (2010). Real Role Models. University of Texas Press: USA.

Terre Blanche, M., Durrhim, K. \& Painter, D. (2006). Research in practice: Applied methods for the social science. University of Cape Town Press: Cape Town

The Holy Bible. (2003). Contemporary English Version. (3rd ed). South Africa: Bible Society of South Africa.

Venter, M.A. (2011). Some Views of Xhosa women regarding the Initiation of their sons. University of South Africa: Pretoria

Vincent, L. (2008). 'Boys will be boys': Traditional Xhosa male circumcision, HIV and sexual socialisation in contemporary South Africa, Culture, Health \& Sexuality, 10 (5): 431-446, June 2008.

Walker, I. (2010). Research Methods and Statistics. Palgrave Macmillan: New York. 